\title{
LAS RELACIONES INTERPERSONALES EN EL PENSAMIENTO DE MARCEL Y LEVINAS: DE LA INTERSUBJETIVIDAD A LA ALTERIDAD ${ }^{1}$
}

\author{
JULIA URABAYEN \\ Universidad de Navarra
}

\begin{abstract}
RESUMEN: Este trabajo es una reflexión en torno a una temática clave en algunas de las corrientes filosóficas actuales más importantes: las relaciones interpersonales. En el siglo xx muchos pensadores optaron por un abordaje diferente de la persona y especialmente de su apertura a los otros. Ello permite ver la confluencia de posturas diversas $y$, a la vez, ofrece un buen punto de partida para aclarar diferencias fundamentales que separan a algunos filósofos que, en principio, parecen cercanos. En concreto, el objetivo de este artículo es abordar las filosofías de Marcel y Levinas mostrando que, a pesar de sus puntos en común, sus antropologías son muy diferentes. Mientras Marcel defiende que la antropología está vinculada, aunque no supeditada, a la ontología; Levinas propone convertir la ética en la filosofía primera. De ahí que las relaciones humanas para Marcel sean intersubjetivas y, en cambio, para Levinas la única manera de abordar al ser humano sea la alteridad.
\end{abstract}

PALABRAS CLAVES: Marcel, Levinas, intersubjetividad, alteridad.

\section{Interpersonal relations in the Thought of Marcel and Levinas: from Intersubjectivity to Otherness}

\begin{abstract}
This article is a reflection on a key theme in some of today's most important philosophical currents: interpersonal relations. In the 20th century many thinkers opted for a different treatment of the person, and especially his or her openness to others. The approach taken in this article will throw light on the confluence of diverse postures and, at the same time, will offer a good starting point for clarifying fundamental differences that separate certain philosophers who, in principle, appear to be very close. Specifically, the objective of this article is to analyze the philosophies of Marcel and Lévinas, showing that, despite what they have in common, their anthropologies are very different. While Marcel holds that anthropology is linked to ontology, although not dependent upon it, Lévinas proposes that ethics should become first philosophy. As a result, for Marcel human relations are intersubjective, while for Lévinas the only way to treat of the human being is via otherness.
\end{abstract}

KEY WORDS: Marcel, Levinas, intersubjectivity, otherness.

Cuando uno se acerca a las obras de Marcel y Levinas, la primera sensación es la de cercanía, afinidad o encuentro. Es más, Levinas suele hablar de Marcel destacando lo que ha 'aprendido' o encontrado en su pensamiento y valorándolo positivamente ${ }^{2}$. Pero, tras ese parecido inicial, surge enseguida la captación

1 Este artículo recoge resultados de la investigación «Mapa de Riesgo Social» financiada por el Ministerio de Economía y Competitividad, Programa de I+D+i orientada a los Retos de la Sociedad, 2013. Referencia: CSO2013-42576-R.

2 Levinas habla de Marcel especialmente cuando se refiere a la polémica contra la centralidad concedida por la filosofía al cogito. Las citas y alusiones a Marcel comienzan en sus escritos de juventud: «en El tiempo y el otro, Levinas cita a Marcel por la misma línea 
de las diferencias; y finalmente la constatación de que hay algo que separa profundamente a estos filósofos.

Uno - Marcel — es presentado por el otro - Levinas - como un filósofo del diálogo y, en cierto modo esa denominación es aceptable, ya que el propio Marcel se entiende a sí mismo como un pensador neosocrático ${ }^{3}$, un filósofo que piensa de manera intersubjetiva o con otros. En cambio, el lituano podría ser considerado un filósofo de la diferencia, un pensador crítico con toda la tradición, especialmente la platónica, en la que el otro, a pesar del diálogo o justo gracias a ese mismo diálogo, es absorbido por y en el mismo perdiendo su radical trascendencia ${ }^{4}$. De ahí que la primera gran dificultad sea encontrar un lenguaje o una terminología que pueda ser usada para referirse a ambos pensadores, más concretamente, para denominar aquella experiencia inicial de la que parten cada uno. Y este no es un problema menor, ya que marca el punto de desacuerdo fundamental entre ambos. Si bien, a la hora de referirnos a Marcel es totalmente correcto hablar de un nosotros, no parece tan claro que lo sea al comentar la obra de Levinas. La alteridad, la absoluta diferencia, no puede ser comprendida como una simple comunidad con otro, pues de ese modo el otro sería un alter ego y la trascendencia se habría perdido nuevamente ${ }^{5}$.

Para poder ver el significado de esta divergencia fundamental es preciso, sin embargo, comenzar por las afinidades o por aquello que ambos pensadores

de pensamiento, por un rejuvenecimiento intelectual, y le tiene en cuenta, después de la fenomenología y Heidegger, a propósito de posibilidades filosóficas que venían mostrándose, de modo que era posible 'darse —o someterse al otro- ideas por 'desentrañar', por 'profundizar' o por 'explorar', como las llama frecuentemente Gabriel Marcel en su Journal Métaphysique'. El arco de las citas a Marcel iniciadas en 1949, se cierra en Entre nous, en el discurso para la inauguración de la Asociación 'Présence de Gabriel Marcel' (1975)», Riva, Franco "Ética como sociabilidad. Buber, Marcel y Levinas», Anuario Filosófico, núm. XXXVIII/2 (2005): 636.

3 Cfr. MARcel, G., Le Mystère de l'être, I (Paris: Présence de Gabriel Marcel, 1997), 5.

4 La comprensión y el discurso tienden a la posesión y dominacion, que solo es total en el asesinato. Cfr. Levinas, E., Entre nosotros. Ensayos para pensar en otro (Valencia: Pretextos, 1993), 21. Pero, a la vez, «el lenguaje, en su función expresiva, se dirige a otro y lo invoca. Ciertamente, no consiste en invocarlo como representado y pensado, pero esto sucede justamente porque el intervalo entre el mismo y el otro - en el que se sostiene el lenguajeno se reduce a una relación entre conceptos que se imitan el uno al otro, sino que describe la trascendencia en la que el otro ya no recae sobre el mismo sino que solamente le obliga, le responsabiliza, es decir, le convierte en hablante. [...] La invocación es anterior a la comunidad. [...] Esta presencia a mí de un ser idéntico a sí es lo que llamamos presencia del rostro", Levinas, E., Entre nosotros. Ensayos para pensar en otro (Valencia: Pre-textos, 1993), 46.

5 Esa comunidad con el otro se funda en el amor, pero este es excluyente: «la emoción que, en la sociedad, funda una sociedad que controla todos sus mecanismos es el amor. Amar es existir como si el amante y el amado estuvieran solos en el mundo. La relación intersubjetiva del amor no es el comienzo sino la negación de la sociedad. [...] El amor es el yo satisfecho por el tú, el que encuentra en otro la justificación de su ser. La presencia del otro agota el contenido de tal sociedad. [...] La sociedad del amor es una sociedad de dos, sociedad de soledades, refractaria a la universalidad», Levinas, E., Entre nosotros. Ensayos para pensar en otro (Valencia: Pre-textos, 1993), 34. 
franceses comparten frente a la filosofía «oficial» (Marcel) o griega (Levinas), pues justo la mayor divergencia entre ambos reside en el punto en el que empieza su trayectoria en común, es decir, su crítica a la filosofía anterior: «está antes que nada el hecho de que en Buber y en Marcel emerge la ruptura con la filosofía tradicional, y una respuesta inédita a la vocación de la filosofía, que la endereza sin retorno hacia las relaciones interhumanas ${ }^{6}$. Aspecto que, a su vez, constituirá el núcleo de la reflexión levinasiana. Tras ese primer momento, habrá que dilucidar con cierto detenimiento las posturas de los dos en torno a la intersubjetividad (Marcel) y la alteridad (Levinas) para poder concluir destacando el desencuentro en torno a esta cuestión central en la obra de los dos.

Este enfoque implica que, a lo largo de las páginas de este trabajo, no se realizará una exposición ni detallada ni completa del pensamiento de estos filósofos, sino que se abordará sus obras desde la perspectiva de las relaciones interhumanas. De igual modo, se procurará no hacer una comparación de los autores vertebrada en torno a apartados dedicados a cada uno de ellos, sino más bien tomando las líneas teóricas y temáticas claves, bien por su proximidad bien por su alejamiento. Así, creemos, se podrá ver con mayor claridad el sentido de cada concepción de lo humano y el significado de la divergencia de cada planteamiento filosófico, lo que explica que uno pueda ser visto como un filósofo del diálogo y el otro como un filósofo de la diferencia.

\section{Ir más ALLÁ dE LA FILOSOFÍA TRADICIONAL, ABRIR UN ESPACIO AL TÚ Y AL OTRO}

Tanto Marcel como Levinas se acercan a la filosofía tradicional desde un enfoque o planteamiento crítico en el que se manifiesta claramente el cansancio respecto a $-\mathrm{O}$ incluso el rechazo de - la filosofía moderna, vista como una manifestación total y cumplida del idealismo que no deja lugar a nada que no sea absorbido por el pensar. Es decir, los dos comparten una visión de la filosofía (en el caso de Levinas de toda la filosofía, en el de Marcel más bien de la moderna) en la que el pensar ha absorbido el ser (Marcel) o la alteridad (Levinas). De ahí la necesidad, igualmente sentida por otros pensadores coetáneos, de salir de esa atmósfera y pensar de nuevo o de otra manera: la filosofía concreta de Marcel y el pensar más allá del ser de Levinas son ejemplos paradigmáticos de esto. En este punto, el lituano valora el giro que supone el planteamiento marceliano y se pregunta «qué significa para el privilegio tradicional de la ontología esta respuesta nueva en la que la fuente y el modelo de lo dotado de sentido se buscan en las relaciones interhumanas» ${ }^{7}$.

Levinas, en un texto dedicado a Marcel y Buber, pone de relieve los dos aspectos en los que estos pensadores suponen una ruptura con la filosofía

6 Riva, F., «Ética como sociabilidad. Buber, Marcel y Levinas», Anuario Filosófico, núm. XXXVIII/2 (2005): 636.

7 Levinas, E., Fuera del sujeto (Madrid: Caparrós, 2002), 35. 
precedente: no sostienen la necesidad de una tematización del otro previa al establecimiento de la relación intersubjetiva por lo que no aceptan la tematización y objetivación como fuente exclusiva del sentido8 ${ }^{8}$ La apelación del otro, del tú para Marcel y Buber, acontece sin una tematización previa, como una invitación en vocativo que da lugar a un encuentro entre dos seres personales que se constituyen como personas precisamente en esa relación. Levinas aceptará este principio característico de la filosofía del diálogo y dará un paso más allá en el reconocimiento de que «en el fondo de mí hay algo distinto de mí, más interior a mí que yo mismo"». Y especialmente cuestionará el papel otorgado por la filosofía clásica a la autarquía: «Marcel, muy pronto, en su Diario metafísico descubrirá la necesidad de pensar con fuerza ese entrelos-dos: 'el valor eminente de la autarkía, del bastarse a sí mismo para sí mismo' es denunciado en la afirmación de que 'solo una relación de ser a ser puede ser llamada espiritual' »" ${ }^{10}$. Dejando de momento para más adelante la delimitación de la diferencia entre la posición de Marcel y la de Levinas al respecto, y siguiendo el hilo marcado por Levinas, se ve inmediatamente la relevancia del modo en el que se presenta el otro o el tú como un ser dotado de sentido más allá de la tematización y la objetivación. Para el lituano el otro se presentará en un contexto, mediado por todas las relaciones sociales y vestido por todas las convenciones. Sin embargo, su sentido es previo o an-árquico, y por eso mismo, podrá juzgarse todo lo cultural, social, histórico y político ${ }^{11}$.

Esta afirmación, en la obra de Marcel, conduce a preguntarse por el modo en el que se accede a ese sujeto que no se presenta mediado por la tematización ni la objetivación. Desde sus primeros escritos aparece una neta preocupación por esa cuestión gnoseológica: ¿cómo acercarse a lo no objetivo sin convertirlo en mera subjetividad? El pensador francés apunta, ya en su Journal Métaphysique, a la fe y más concretamente al amor ${ }^{12}$. Se da un conocimiento objetivo del otro ser personal que únicamente lo ve como un él, como una fuente de información o como un objeto de discurso o saber. Pero ése no es el único modo de conocimiento, pues es posible conocer un ser personal más allá del saber objetivo y alcanzarlo como ser personal y libre ${ }^{13}$. Ese modo de conocimiento es el amor, que es una captación del ser que pone en marcha y ayuda a la creación de la individualidad propia y del ser amado. Es un conocimiento que unifica, que supera la dispersión, y que fomenta las potencialidades del

8 «La 'filosofía del diálogo' atestigua también la puesta en cuestión de la inteligibilidad exclusiva del fundamento y la puesta en cuestión de la objetivación e incluso de la tematización como únicas fuentes de lo dotado de sentido», Levinas, E., Fuera del sujeto (Madrid: Caparrós, 2002), 45.

9 Conesa, D., «Soluciones a la crisis del sentido de lo humano. Una aproximación a Marcel y Levinas», Anuario Filosófico, núm. XXXVIII/2 (2005): 540.

10 Levinas, E., Fuera del sujeto (Madrid: Caparrós, 2002), 37.

11 Cfr. Levinas, E., Entre nosotros. Ensayos para pensar en otro (Valencia: Pre-textos, 1993), 217.

12 Cfr. Marcel, G., Journal Métaphysique (Paris: Gallimard, 1997), 58.

13 Cfr. MARcel, G., Etre et Avoir (Paris: Éditions Universitaires, 1991), 154. 
ser amado que solo son cognoscibles por medio del amor ${ }^{14}$. El amor no capta predicativa o temáticamente el ser del amado, no se fija en sus cualidades ni nace de una afinidad de gustos. Aprehende su ser y de ahí que pueda afirmar su valor absoluto, lo que es perdurable, y apelar al otro para que dé cumplimiento a esas posibilidades. Por ello Marcel lo considera una experiencia ontológica, un acto único en el que un ser personal llama libremente a otro ser libre capaz de responder y dar lugar al encuentro personal en el que el nosotros es un yo con un tú en comunión: "no comunico efectivamente conmigo mismo más que en la medida en que comunico con el otro, es decir, en que éste llega a ser un tú para mí» ${ }^{15}$.

En esta forma de acceso al otro ser personal como un tú libre y no como un objeto, Levinas encontrará un modo de quebrar la prioridad del cogito encerrado en sí mismo y de establecer la afirmación de la necesidad del otro para constituir la identidad, o la intimidad en la terminología marceliana. Pero ese es el único punto que tendrán en común, ya que el lituano no aceptará que la verdadera experiencia del otro sea la que lo capta como un tú, lo que establece una comunión de dos en un nosotros que como tal es exclusiva y excluyente del tercero. Para Levinas el amor no es el modo de conocimiento ni de acceso al otro ${ }^{16}$ : él buscará esa salida del ser hacia la alteridad en el tiempo y más concretamente en la ética ${ }^{17}$. Es más, mostrará una importante reticencia hacia el amor y la pequeña comunidad de un nosotros encerrada en sí misma y autosuficiente, que no necesita ni tolera a nadie junto a su perfecta unidad autosatisfecha y ególatra ${ }^{18}$. Además, el planteamiento marceliano, según

14 Cfr. Marcel, G., Journal Métaphysique (Paris: Gallimard, 1997), 63-64. Levinas glosa estas ideas del siguiente modo: «acercamiento de interpelación, relación de Yo-Tú, es decir, relación fundamentalmente otra que la percepción del otro en su naturaleza o en su esencia, la cual desemboca en verdades o en opiniones expresadas a modo de juicios, como la experiencia de un objeto cualquiera», Levinas, E., Fuera del sujeto (Madrid: Caparrós, 2002), 37.

15 Marcel, G., Filosofía concreta (Madrid: Revista de Occidente, 1959), 46.

16 A pesar de ello reconoce el valor de lo afirmado por Marcel sobre el amor, acercándolo a sus propias posiciones: «es ante todo cuestión de ser, de espíritu y de lo espiritual, y al final se nombra el amor. Pero este ser no es conciencia de sí, es relación con lo distinto de sí y despertar. Pero, ¿lo distinto de sí mismo no es el Otro? Y el amor significa, ante todo, acoger a otro como tú, es decir, con los brazos abiertos. El espíritu no es lo Dicho, es el Decir que va del Mismo al Otro sin suprimir la diferencia. Se abre un paso allí donde no hay nada común. ¡No se trata de la indiferencia del uno para el otro! Bajo la espiritualidad del yo despertado por el tú, Marcel, coincidiendo en ello con Buber, designa una nueva forma de significar. Ni la no-identidad de lo idéntico y lo no-idéntico ni su identidad. A pesar de que los escritos de Marcel restauran tantas formas e instituciones tradicionales, vista desde el Diario esta obra tan importante se descubre elaborada y consumida por esa nueva forma de significar el sentido», LEVINAS, E., Entre nosotros: ensayo para pensar en otro (Valencia: Pre-Textos, 1993), 82-83.

17 Cfr. Levinas, E., Entre nosotros. Ensayos para pensar en otro (Valencia: Pre-textos, 1993), 161-184.

18 No por ello lo rechazará, sino que lo entenderá como responsabilidad: «el encuentro con Otro es ante todo mi responsabilidad respecto de él. Este hacerse responsable del prójimo es, sin duda, el nombre serio de lo que se llama amor al prójimo, amor sin Eros, caridad, un amor en el cual el momento ético domina sobre el momento pasional, un amor sin 
Levinas, continúa apresado en la ontología, ya que «tanto Buber como Marcel caracterizan la relación Yo-Tú en términos de ser. 'Entre-los-dos' es un modo de ser: la co-presencia, el co-esse. Si seguimos literalmente los textos, el ser, la presencia, siguen siendo la última referencia del sentido» ${ }^{19}$.

Para cumplir el proyecto marceliano de superar la objetividad o tematización como única fuente de sentido, lo que liberaría el acceso a la intersubjetividad, Levinas considerará necesario ir más allá de la ontología, «salir del ser» ${ }^{20}$. El primer paso consiste en incidir en el tiempo, en la diacronía, frente a la sincronía de la presencia del $\operatorname{ser}^{21}$. Estos son los temas de sus primeros escritos, especialmente de Le temps et l'autre, obra en la que mediante un lenguaje metafórico, analógico e indirecto trata de establecer la cercanía de la temporalidad y la alteridad, lo que es sintetizado en otra de sus obras de juventud del siguiente modo: «¿no será la sociabilidad, más que la fuente de nuestra representación del tiempo, el mismo tiempo? Si el tiempo se constituye por medio de mi relación con el otro, el tiempo es exterior a mi instante, pero es también otra cosa que un objeto dado a la contemplación. La dialéctica del tiempo es la dialéctica misma de la relación con el otro» ${ }^{22}$. Esa diacronía frente a la sincronía del ser afecta al pensamiento de Marcel, ya que la relación intersubjetiva o la comunidad es una forma de proximidad, una copresencia previa a la tematización de la conciencia, pero copresencia sincrónica aquí y ahora. Levinas rompe así con Marcel y exige que la irreductibilidad de la intersubjetividad se aplique no solo al saber, sino también al ser ${ }^{23}$. Además, considera que esa sociabilidad liberada del fundamento del saber es la ética ${ }^{24}$, que «comienza ante la exterioridad de lo

concupiscencia. No me gusta demasiado el término 'amor', adulterado por el uso», Levinas, E., Entre nosotros. Ensayos para pensar en otro (Valencia: Pre-textos, 1993), 129.

19 Levinas, E., Fuera del sujeto (Madrid: Caparrós, 2002), 38. Y el texto continúa: «sin embargo, sería importante ver si los dos filósofos se vuelven hacia el lenguaje ontológico por el mismo motivo, si, en Buber, la ruptura con la ontología no se anuncia más radical, si la persistencia en él de la ontología no es más insólita que en Marcel quien liberado de una manera tan notable de toda escuela y de toda escolástica, y tan deliberadamente hostil a la interpretación objetivista del ser, sigue estando de todos modos profundamente enraizado en la ontología, a pesar de todos los trastornos que la noción de Tú introduce en ella».

20 Levinas, E., Ética e infinito (Madrid: La balsa de la Medusa, 1982), 56. Esta idea aparece por primera vez en De l'évasión (Paris: Fata Morgana, 1987), 71-74.

21 Cfr. Levinas, E., Entre nosotros: ensayo para pensar en otro (Valencia: Pre-Textos, 1993), 94-95.

22 Levinas, E., De la existencia al existente (Madrid: Arena Libros, 2000), 127.

23 Tanto Buber como Marcel suponen la superación del saber como fundamento del sentido, y apuntan a la sociabilidad, más allá de la verdad y los juicios de saber. Pero no superan el ser. Cfr. Levinas, E., Fuera del sujeto (Madrid: Caparrós, 2002), 37-38.

24 «Lo que pretendemos es intentar contemplar la ética en relación con la racionalidad del saber inmanente al ser, que es primordial para la tradición filosófica de Occidente, ya que la ética puede incluso - sobrepasando a fin de cuentas las formas y determinaciones de la ontología y sin renunciar por ello a la paz de lo Racional- acceder a otro proyecto de inteligibilidad y a otra forma de amar la sabiduría», Emmanuel Levinas, Entre nosotros. Ensayos para pensar en otro (Valencia: Pre-textos, 1993), 9. 
otro, ante lo otro, y, como nos gusta decir, ante su rostro que compromete mi responsabilidad por su expresión humana, la cual precisamente no puede, sin alterarse, fijarse, ser mantenida objetivamente a distancia ${ }^{25}$.

Esa irreductibilidad y ese modo de acercamiento es la ética: el otro no solo será diacrónico, alteridad absoluta que es trascendencia infinita, sino que hará su entrada en el mundo fenoménico manteniendo su distancia e imponiendo en imperativo un mandato que exigirá por parte del yo una responsabilidad ilimitada que lo convertirá en rehén y no en sujeto: «la significación, el unopara-el-otro, la relación con la alteridad, ha sido analizada como proximidad; esta proximidad lo ha sido como responsabilidad respecto al otro y la responsabilidad con el otro lo ha sido como substitución. En su subjetividad, en su mismo porte de sustancia separada, el sujeto se ha mostrado como expiación-por-el-otro, como condición o incondición de rehén» ${ }^{26}$.

Está claro que Marcel no llega a tales afirmaciones, pero nuevamente, el lituano señala que ha encontrado en el pensador neosocrático una indicación muy valiosa para quebrar el solipsismo y alcanzar el fuera del sujeto que permite establecer que «el yo no es ya el punto central ni inicial, ni final del todo» ${ }^{27}$. Esa noción no es otra que la encarnación: «Levinas se muestra como un lector bastante atento de Ser y tener, del que recuerda la definición de la encarnación como la situación de un yo ligado a un cuerpo; el cogito como algo dado no transparente para sí mismo; el tema consiguiente de la centralidad de la sombra (respecto a la luz cartesiana); la imposibilidad precisamente de circunscribir en un saber la propia corporeidad; la salida, en fin, del cuerpo de la concepción instrumental a través del 'mediador absoluto' ${ }^{28}$. Tanto para Marcel como para Levinas la corporalidad juega un papel fundamental a la hora de comprender el ser humano y las relaciones interhumanas. El hombre es un ser corporal que mantiene relaciones con su corporalidad y con los otros seres gracias a su cuerpo $^{29}$. Esta comprensión del ser humano concreto, existente, corporeizado que ya está en Marcel es central en las obras de Levinas, especialmente en las de juventud y en Totalidad e infinito. En el siguiente apartado se analizará con más detenimiento esta temática. Lo que me gustaría señalar aquí es que la corporalidad o encarnación es otro de los puntos de encuentro en su visión del ser humano y de las relaciones interhumanas, y que en este aspecto son mayores las afinidades que las diferencias.

25 Levinas, E., Fuera del sujeto (Madrid: Caparrós, 2002), 50.

26 Levinas, E., De otro modo que ser o más allá de la esencia (Salamanca: Sígueme, 1999), 265. Este es el núcleo de su ética, esa vulnerabilidad, esa imposibilidad de poder que «refleja el Infinito en los rostros humanos», Emmanuel Levinas, Entre nosotros. Ensayos para pensar en otro (Valencia: Pre-textos, 1993), 20.

27 Levinas, E., Fuera del sujeto (Madrid: Caparrós, 2002), 32.

28 Riva, F., «Ética como sociabilidad. Buber, Marcel y Levinas», 650. Cfr. Levinas, E., Fuera del sujeto (Madrid: Caparrós, 2002), 40-41. El desarrollo más detenido del papel de la encarnación se encuentra en Gabriel Marcel, Filosofía concreta (Madrid: Revista de Occidente, 1959), 21-49.

29 Cfr. MARcel, G., Journal Métaphysique (Paris: Gallimard, 1997), 19-20. 
Además, en la profundización de la encarnación y de la relación que el ser humano tiene/es con su cuerpo se perfila una de las nociones más destacadas de su pensamiento: el misterio ${ }^{30}$. Este término, que proviene del lenguaje religioso, pero es tomado en un sentido filosófico, tiene en Marcel una dimensión gnoseológica y otra ontológica. Y es esta noción la que encontramos en los escritos de juventud de Levinas al referirse al momento en el que el ser humano se topa con la muerte, con esa realidad que desmonta el sujeto, que muestra su impotencia ${ }^{31}$. Es decir, Levinas mantiene esa dimensión gnoseológica y ontológica de una realidad que es superior al ser humano, pero la desplaza de ámbito por lo que modifica su sentido: en Marcel es lo que abarca, lo que somos sin poder delimitar o cercar y es, a la vez, la presencia en el ser humano de Dios, de lo que no siendo él mismo es más íntimo que el yo ${ }^{32}$; en Levinas es lo que no somos y nos desmonta poniendo de relieve nuestra falta de poder o soberanía, nuestro no ser sujetos soberanos de todo, pero solo cuando la confrontación sea con la alteridad y no con la muerte lo otro será constitutivo y más íntimo que el propio yo.

Como se ha visto en este apartado, son muchos los temas en común y varias las afirmaciones levinasianas que ponen de relieve que acepta a Marcel como un precedente suyo y que conoce bien su pensamiento, con el que siente cierta afinidad $^{33}$. Pero también es patente que esas apropiaciones son parciales y siempre al hilo de una reflexión realizada desde una perspectiva crítica, personal y diferente. En el siguiente apartado se desarrollarán con más detenimiento estas diferencias esenciales presentando con más detalle sus reflexiones acerca de las relaciones interhumanas. En este punto solo retendremos una matización que Levinas establece sobre el encuentro en el marco de la confrontación de Marcel y Buber: «henos aquí, más allá de la Relación buberiana, pero en el corazón de la co-presencia, participación que funda toda relación. La co-presencia no es un diálogo. Nexo intersubjetivo más profundo que el lenguaje, el cual estaría arrancado, según Marcel, de esta comunicación originaria. Principio de alienación, el lenguaje petrificaría la comunicación viva: precisamente al hablar

30 Cfr. Marcel, G., Journal Métaphysique (Paris: Gallimard, 1997), 159-161.

31 Levinas, E., Le temps et l'autre (Paris: Fata Morgana, 1979), 20.

32 «Es una de las consecuencias del análisis marceliano del misterio ontológico: el sujeto no es completamente de sí mismo. El ser divino que no somos, un Tú absoluto que encontramos como transcendente, es también el ser que nos sostiene y nos ama. [...] El misterio del ser es la manera en la que nuestro ser que 'va a Dios' pertenece ya a Dios y es la manera en que el ser de Dios sujeta el 'yo' del hombre. El yo del hombre ya no es el punto central, ni inicial, ni final, del Todo», Levinas, E., Fuera del sujeto (Madrid: Caparrós, 2002), $42-43$.

33 En el discurso de apertura de la Asociación Gabriel Marcel lo llama filosofía paterna y destaca netamente la novedad y las posibilidades que abre, llegando a establecer que «en esta ruptura y en este despertar, en esta expiación y en esta exaltación, se despliega la divina comedia de una trascendencia que está más allá de las posiciones ontológicas», Levinas, E., «Una nueva racionalidad. Sobre Gabriel Marcel» en Entre nosotros. Ensayos para pensar en otro (Valencia: Pre-Textos, 1993), 83. 
es cuando pasamos con más facilidad del 'Tú' al 'Él' o a 'Esto', y objetivamos al otro. Mientras que para Buber decir 'tú' es una relación absoluta que no tiene detrás de sí ningún principio fundador, Marcel se opone al lenguaje entendido como elemento del encuentro; se opone al mismo término de Relación prefiriendo precisamente el de encuentro o el de tensión (Spannung)» ${ }^{34}$. De ahí que Levinas sienta una mayor afinidad con Marcel que con Buber. A pesar de ello, el lenguaje originario de Levinas no será un diálogo de dos tús que corren el riesgo de convertirse en dos é ${ }^{35}$.

\section{Dos CAMINOS QUE DIVERGEN: INTERSUBJETIVIDAD Y ALTERIDAD}

Una vez establecidas brevemente las relaciones generales y los puntos de acercamiento y alejamiento, es el momento de abordar de modo directo y con algo más de extensión el tema central del trabajo: el nosotros o, más concretamente, si existe tal nosotros y cómo lo ve cada uno de los pensadores estudiados. Ya hemos señalado que en el caso de Marcel la intersubjetividad es un tema clave. Aparece como objeto de reflexión y como noción en sus escritos de juventud, tanto en las obras filosóficas como en las dramáticas, que son, en su gran mayoría, piezas teatrales dedicadas a poner de relieve las enormes dificultades a las que se enfrentan las relaciones humanas. De hecho, de alguna manera, es la pregunta inicial y el sentido o luz que dirige su pensamiento, ya que como él mismo indicó su reflexión comienza con la pregunta por la muerte, no por la muerte propia, sino por la muerte del otro; más concretamente la de su madre. Es decir, su vocación filosófica nace de una intensa preocupación por el tú amado, por el nosotros que es quebrado por la muerte. Y se refuerza o nutre con otra experiencia intersubjetiva también profundamente unida a la muerte: su trabajo en el servicio de información de la Cruz Roja sobre los desaparecidos durante la Primera Guerra Mundial. Este es el punto de inflexión en su ya comenzada trayectoria filosófica, la vivencia dramática que le alejará del idealismo para el que la vida y la muerte de los seres individuales carecen de importancia.

Este es el suelo nutricio de la obra marceliana, como la Shoah será el trasfondo de gran parte de la obra levinasiana. De niño, Emmanuel Levinas escuchaba en el insomnio, en la imposibilidad de dormir, mientras los mayores siguen su vida, el ruido sordo del peso del ser, por lo que posteriormente buscó la salida de ese ser neutro, anónimo e impersonal ${ }^{36}$. Más tarde ese anonimato del ser se convirtió en el anonimato de la muerte en masa en los campos de

34 Levinas, E., Fuera del sujeto (Madrid: Caparrós, 2002), 42.

35 Ello es así porque para Levinas el lenguaje está fundado «en una relación anterior a la comprensión y que constituiría su razón», Levinas, E., Entre nosotros. Ensayos para pensar en otro (Valencia: Pre-textos, 1993), 16.

36 Cfr. Levinas, E., Ética e infinito (Madrid: La balsa de la Medusa, 1982), 43-44. 
exterminio y en la culpabilidad del superviviente, de quien ha perdido a toda su familia (excepto su mujer y su hija) en esos campos en los que hasta la muerte es despojada de su sentido humano y personal ${ }^{37}$. Es decir, se trata de experiencias humanas de gran calado y de extrema dureza que agudizan la necesidad de reactivar la pregunta por el ser humano, por el sentido de su existencia y por las dificultades de las relaciones interhumanas. A pesar de lo demoledor de esas vivencias, tanto Marcel como Levinas tratarán de garantizar la posibilidad y la riqueza de las relaciones entre seres humanos. Pero lo harán de modos diferentes. Los dos buscarán el camino hacia el establecimiento de unos lazos humanos que permitan rehabilitar la ética, no reducirla a una farsa ${ }^{38}$, pero para Marcel la ética se apoyará en la ontología y para Levinas será la filosofía primera.

La relevancia de la intersubjetividad, de la apertura, de la salida de sí, del otro en el mismo o alteridad no reducida a la mismidad no se debe únicamente a la necesidad de los otros, a la natural tendencia a establecer relaciones de comunicación, relaciones sociales o políticas entre seres humanos. Esa apertura es mucho más profunda, ya que es inherente a la propia constitución del yo o de la identidad personal. Marcel marca desde el principio la precedencia de la intersubjetividad sobre la intimidad, aunque, como se verá, conservará un núcleo de intimidad y le otorgará un peso con el que Levinas romperá al poner la iniciativa de la apertura en el otro y la responsabilidad como previa a las intenciones ${ }^{39}$. En una de sus obras más importantes — por la madurez de su pensamiento y por ser la más «sistemática» o la más articulada- Marcel establece que «la realidad personal de cada uno es ella misma intersubjetiva $»^{40}$. De ahí que en un estudio antropológico se tenga que comenzar por las relaciones interhumanas y no por la persona en su intimidad ${ }^{41}$, lo que separa a Marcel de otras posturas anteriores.

Esta tesis, que rompe con el solipsismo y la autarquía del yo, y es común a Levinas $^{42}$, le lleva a realizar un análisis de los diferentes modos de apertura a los otros. Lo que supone que, a diferencia de Levinas, Marcel elabora con más detenimiento un pensamiento que podría ser denominado socio-político. Este

37 Cfr. Arendt, H., Los orígenes del totalitarismo (Madrid: Alianza Editorial, 2006), capítulos 12 y 13 .

38 Levinas, E., Totalité et infini. Essai sur l'exteriorité (La Haye: Nijholf, 1971), 47.

39 Cfr. Levinas, E., Entre nosotros. Ensayos para pensar en otro (Valencia: Pre-textos, 1993), 15.

40 Marcel, G., Mystère de l'être II (Paris: Présence de Gabriel Marcel, 1997), 161.

${ }_{41}$ Esta se constituirá gracias a diversas experiencias como la fidelidad, el compromiso, el amor y la promesa, que implican la presencia de la intersubjetividad. Cfr. MARCEL, G., Etre et avoir (Paris: Éditions Universitaires, 1991), 36-41. Y la esperanza, estudiada principalmente en Marcel, G., Homo Viator. Prolégomènes à une métaphysique de l'espérance (Paris, Présence de Gabriel Marcel, 1998), 37-86.

42 Este es el núcleo del humanismo del otro que no concibe al sujeto como soberano, sino como pasividad. Cfr. Levinas, E., Entre nosotros. Ensayos para pensar en otro (Valencia: Pre-textos, 1993), 137-138. 
estudio, como todos los suyos, es concreto y se basa en ejemplos y situaciones vividas, por lo que no tiene pretensión alguna de exhaustividad ni de ser completo. La manera en la que la intersubjetividad toma cuerpo es variada, aunque puede concentrarse en ciertos tipos: el amor y la amistad, la familia, la comunidad humana y la relación personal con Dios. Como es lógico gran parte de estas temáticas están presentes en el pensamiento levinasiano, especialmente en las obras de la primera etapa y en su culminación en Totalidad e infinito.

La afirmación de la precedencia de la intersubjetividad sobre la intimidad implica, en primer lugar, un claro rechazo de la noción de autonomía. Marcel no aceptó la definición del hombre como ser autónomo, pues, para él, este término no es propio del orden del ser y de la libertad, sino del de lo gestionable, de lo problemático y de las cosas tenidas ${ }^{43}$. Asentar una ética sobre la noción de autonomía es para Marcel un error: «me inclino a pensar que la idea de autonomía está vinculada a una especie de reducción o de particularización del sujeto. Cuanto más integralmente entro en acción, es menos legítimo decir que yo soy autónomo (en este sentido el filósofo es menos autónomo que el sabio, el sabio mismo es menos autónomo que el técnico). La autonomía vinculada a la existencia de una esfera de actividad rigurosamente circunscrita. Si esto es así, toda la ética kantiana reposa sobre un monstruoso contrasentido, una especie de aberración especulativa ${ }^{44}$. Según Marcel, la vida no es gestionable y, por lo tanto, la autonomía no es aplicable a este ámbito, como tampoco lo es la heteronomía: «a una cierta profundidad de mí, y en una zona donde las especificaciones prácticas se funden (en el sentido de 'fundir' más bien que de 'fundar') los términos de autonomía y de heteronomía se convierten en inaplicables» ${ }^{45}$.

Para Marcel el ámbito de la moralidad supera la autonomía y la heteronomía, puesto que es el del amor. Más allá del tener y lo gestionable, y la moralidad lo está, esta categoría de autonomía no tiene validez ${ }^{46}$. El orden de la libertad es el de la disponibilidad y el amor. Para Marcel la ética kantiana, por ser una ética de la autonomía, desconoce que la libertad no se reduce a autonomía, sino que está en el orden del ser. Además, según Marcel, el giro copernicano realizado por Kant y la creencia en la autonomía del hombre puede acabar degenerando en un orgullo de la razón y en una deificación del hombre que conduzca a un antropocentrismo ${ }^{47}$. En cambio, la libertad se alcanza únicamente cuando se supera el ensimismamiento al que conduce la idea de autonomía. La libertad es, según Marcel, apertura a los otros ${ }^{48}$. Esto significa

43 Cfr. MARCEL, G., Etre et avoir (Paris: Éditions Universitaires, 1991), 91. La descalificación de la autosuficiencia, el rechazo a la autonomía y la crítica a Kant aparecen ya en MARCEL, G., Journal Métaphysique (Paris: Gallimard, 1997), 206-210.

44 Marcel, G., Être et avoir (Paris: Éditions Universitaires, 1991), 92.

45 Marcel, G., Être et avoir (Paris: Éditions Universitaires, 1991), 93.

46 Cfr. Marcel, G., Etre et avoir (Paris: Éditions Universitaires, 1991), 93. Cfr. MARcel, G., Journal Métaphysique (Paris: Gallimard, 1997), 119-120.

47 Cfr. Marcel, G., Filosofía concreta (Madrid: Revista de Occidente, 1959), 45.

48 Cfr. Marcel, G., Le mystère de l'être, II (Paris: Présence de Gabriel Marcel, 1997), 115. 
concebir la libertad como apertura y especialmente acabar con la idea de que la libertad es fundamentalmente libertad de elección o indeterminación, pues «la libertad de indiferencia es el grado más bajo de libertad» ${ }^{49}$. La libertad es para Marcel un acto creativo que contribuye a hacerse uno mismo, algo que hay que conquistar ${ }^{50}$ y esa conquista se lleva a cabo con otros. Es, por tanto, a diferencia de lo que sostendrá Levinas, una iniciativa del sujeto, de un sujeto que es apertura al otro, pero que sigue conservando su carácter de inicio.

Frente a lo cual, Levinas optará por la heteronomía concibiendo la libertad como la aceptación del mandato, lo que no esclaviza ni humilla al yo, sino que lo constituye y únicamente a partir de esa radical e inicial heteronomía, el sujeto podrá conquistar su identidad y decir nosotros: «respetar no puede significar someterse, aunque no obstante el otro me manda. Se me manda, es decir, se me reconoce como capaz de obrar. Respetar no es inclinarse ante la ley, sino ante un ser que me manda hacer algo. Pero, para que este mandato no comporte humillación alguna — pues ello me retiraría la mera posibilidad de respetar-, el mandato que recibo debe ser al mismo tiempo el mandato de mandar a quien me manda. Consiste en mandarle que me mande. Esta referencia de mandato a mandato consiste en el hecho de decir 'Nosotros', de tomar partido. Debido a esta referencia de un mandato a otro, Nosotros no es el plural de Yo» ${ }^{51}$.

Estas ideas levinasianas suponen una mayor ruptura con la tradición filosófica que el planteamiento marceliano. El sujeto es, en realidad, sujeto-a, rehén del otro que manda e impone una orden ética que se concreta en «no matarás $»^{52}$. El sujeto sujetado escucha la orden que está inserta en el rostro, en la vulnerabilidad que puede ser rasgada únicamente por el asesinato, pero contiene su poder de poder y detiene su mano, como Abraham. En esta noción de sujeto, la libertad es también una sujeción aceptada de una orden ética que es superior a uno mismo, un acatamiento que constituye al sujeto en lo que es dotándolo de una responsabilidad asimétrica y total ${ }^{53}$, que es el principio de individuación ${ }^{54}$. Es, además, una responsabilidad an-arquica ${ }^{55}$ que muestra que ser para el otro es ser responsable de su responsabilidad ${ }^{56}$.

49 Marcel, G., Mystère de l'être II (Paris: Présence de Gabriel Marcel, 1997), 116.

50 Cfr. Marcel, G., Dignité humaine et ses assises existentielles (Paris: Aubier-Montaigne, 1964), 190.

51 Levinas, E., Entre nosotros. Ensayos para pensar en otro (Valencia: Pre-textos, 1993), 48-49. Estas ideas son elaboradas especialmente en "Libertad y mandato» en La realidad y su sombra. Libertad y mandato. Trascendencia y altura (Madrid: Trotta, 2001), 67-84.

52 El mandato es el rostro ex-puesto, la orden que yace en el rostro es ¡No matarás! Cfr. Levinas, E., La huella del otro (México: Taurus, 1998), 103.

53 Cfr. Levinas, E., Entre nosotros. Ensayos para pensar en otro (Valencia: Pre-textos, 1993), 133.

54 Cfr. Levinas, E., Entre nosotros. Ensayos para pensar en otro (Valencia: Pre-textos, 1993), 133-134.

55 Cfr. Levinas, E., Entre nosotros. Ensayos para pensar en otro (Valencia: Pre-textos, 1993), 198.

56 Cfr. Levinas, E., Ética e infinito (Madrid: La balsa de la Medusa, 1982), 90. 
Así pues, la responsabilidad, y no la libertad, es la que constituye al sujeto. De ahí que la relación con el otro sea asimétrica y no establezca una comunidad de iguales o semejantes: el otro está antes y es prioritario respecto al yo, que, para Levinas, se desgarra y en su desgarramiento es quien tiene que ser: oído atento que responde sin condiciones "heme aquí» responsable de todo y de todos. Es decir, el sujeto levinasiano es pasividad más pasiva que la pasividad, no actividad ni iniciativa. Así se sale tanto del ser como del sujeto soberano y se coloca la ética como filosofía primera: «el antihumanismo moderno, al negar el primado que representaría en el ser la persona como fin de sí misma, y al buscar, pues, ese sentido en la pura y simple configuración de elementos, deja quizá lugar para la subjetividad como sustituta. No es solamente que el yo sea un ser dotado de ciertas cualidades que llamamos morales, y que serían como sus atributos; es que la infinita pasividad, o pasión, o paciencia del Yo — su sí mismo- constituye su unicidad esencial, a la que se ve conducido quien es este acontecimiento incesante de sustitución, este hecho de que el ser se vacía de su ser ${ }^{57}$.

Esto, por otra parte, muestra el sentido de lo humano: «la santidad también puede acontecer en lo humano. Uno puede morir por el otro. No puedo probarlo estadísticamente; si lo hiciera, siempre partiríamos de esta perseverancia del ser en el ser. Y lo humano siempre ha visto lo santo como humano. El único valor que no puede ser negado es el de la santidad. Y la santidad es la posibilidad de sentir más intensamente el ser-para-la-muerte del otro que mi propio ser-parala-muerte. Esto no prueba nada. Pero siempre que algo así ocurre decimos que en realidad es humano ${ }^{58}$. La carga del «heme aquí» es, por tanto, la suprema dignidad humana ${ }^{59}$.

Este debate sobre la libertad y el ser, por otra parte, es el punto en el que Marcel entronca con la diferencia de tener y $\operatorname{ser}^{60}$, y más concretamente, con la encarnación. El ser humano es un ser que es su cuerpo, teniendo en cuenta que tal afirmación no supone un materialismo, sino la correcta integración de la corporalidad en la identidad humana ${ }^{61}$. Además, gracias a su corporalidad específica y diferenciada del resto de los seres vivos, el hombre es capaz de tener y manipular cosas (relaciones de posesión y utilización) y es igualmente capaz de entablar relaciones con lo que existe en tanto que existente (relaciones

57 Levinas, E., Entre nosotros. Ensayos para pensar en otro (Valencia: Pre-textos, 1993), 77.

58 Levinas, E., La huella del otro (México: Taurus, 1998), 102-103.

59 Cfr. Levinas, E., Ética e infinito (Madrid: La balsa de la Medusa, 1982), 96.

60 Esta distinción aparece en Gabriel Marcel, Journal Métaphysique (Paris: Gallimard, 1997), 152 y es el núcleo de su segundo Diario, titulado Etre et avoir, especialmente en las páginas 58-60, 94-95, 103-108, 111-125.

61 Marcel considera que la noción de cuerpo no es unívoca y que hay dos tipos de relación con él: el cuerpo objeto y el cuerpo sujeto. Cfr. MARcel, G., Journal Métaphysique (Paris: Gallimard, 1997), 124 y 236-242, 262-263. Esta noción de cuerpo propio y su diferencia respecto al cuerpo perceptible es recogida por Levinas. Cfr. Levinas, E., Entre nosotros. Ensayos para pensar en otro (Valencia: Pre-textos, 1993), 212. 
existenciales) $)^{62}$. Es decir, se abre de este modo el ámbito de la economía ${ }^{63}$, que Levinas abordará con detenimiento especial en Totalidad e infinito. Ensayo sobre la exterioridad, siguiendo principalmente los análisis de Heidegger en Ser y tiempo; y se abre igualmente un ámbito de relaciones existenciales que también aparecerá en los textos de juventud de Levinas en torno a la diferencia existencia/existente y las experiencias que permiten captar esa diferencia ontológica: la náusea, la pereza, el cansancio, el insomnio ${ }^{64}$.

Puesto que ya hemos realizado el estudio pormenorizado de los aspectos relativos a las diferentes formas de la intersubjetividad en otros textos y que el presente trabajo no requiere entrar en una exposición detallada de los mismos, nos limitaremos a retomar, en segundo lugar, los núcleos centrales para nuestro objetivo: comparar la visión marceliana y levinasiana de lo interhumano. Comenzaremos, por tanto, con la presentación general de la intersubjetividad por parte de Marcel. El pensador francés sostiene que el hombre se convierte en persona en la apertura a los otros seres humanos, ya que en esa apertura se gana o se pierde en sentido pleno. Es decir, la intersubjetividad implica y compromete a la persona en su totalidad, facilitando su creación como ser libre y responsable. Así sentencia Marcel «me afirmo como persona en la medida en la que creo realmente en la existencia de los otros $\aleph^{65}$.

De este modo se tiene una certeza o más bien una seguridad existencial de la existencia de los otros, así como de la propia existencia, y de la apertura inherente a ellos. Sin esa apertura no hay yo y, por eso, la intersubjetividad es condición ontológica de la subjetividad. Pero también es condición de perfeccionamiento, ya que no solo hace ser, sino que hace ser plenamente al yo. Este segundo papel ha llevado a preguntarse si es realmente posible para Marcel la existencia de un sentido negativo de la intersubjetividad; es decir, si la apertura al tú podría dificultar o impedir la constitución del yo. Dado que, como ve muy bien Ricoeur, la intersubjetividad es disponibilidad y ésta es el gozne de la ontología y la ética ${ }^{66}$, ésta es una cuestión fundamental. Creemos que en el pensamiento marceliano la intersubjetividad siempre tiene un sentido positivo; si la apertura es clausurada simplemente no hay intersubjetividad, si

62 Cfr. Marcel, G., Journal Métaphysique (Paris: Gallimard, 1997), 15. 1993), 43

Cfr. Levinas, E., Entre nosotros. Ensayos para pensar en otro (Valencia: Pre-textos,

${ }_{64}$ Estas experiencias son analizadas principalmente en De l'évasion (Paris: Fata Morgana, 1987) y en De l'existence à l'existant (Paris: Vrin, 1981).

${ }_{65}$ Marcel, G., Homo Viator. Prolégomènes à une métaphysique de l'espérance (Paris: Présence de Gabriel Marcel, 1998), 26. De ahí que considere un pseudoproblema fruto del solipsismo la demostración de la existencia de los otros. Cfr. Marcel, G., Etre et avoir (Paris: Éditions Universitaires, 1991), 73-75. De igual modo se da una seguridad existencial inmediata de la existencia de la realidad. Cfr. MARcel, G., Journal Métaphysique (Paris: Gallimard, 1997), 3.

66 Ricoeur, P., Les colloques de la Bibliothèque Nationale, Colloque organisé par la Bibliothèque Nationale et l'Association Présence de Gabriel Marcel (Paris: Bibliothèque Nationale, 1989), 157-167. 
es degradada o empobrecedora, estamos ante la indisponibilidad ${ }^{67}$, bien del otro bien del yo.

Esto supone que la apertura es constitutiva de la intimidad ${ }^{68}$, de la subjetividad, y la lleva a su plenitud ya que solo es tal si lo logra. En Levinas, la apertura no será constitutiva del yo, sino que la aportará el otro ${ }^{69}$. Únicamente si el yo acoge al otro - el otro en el mismo- sin absorberlo en su mismidad, se cumplirá la salida, el éxodo, la verdadera llegada de la trascendencia y la auténtica constitución del sujeto como rehén ${ }^{70}$. Si el otro llega y el yo no lo acoge, lo que sucede muy a menudo, no se ha producido la ruptura de la totalidad y del solipsismo. Ulises recorrerá la totalidad del mundo conocido, pero permanecerá inmune a la alteridad y mantendrá su objetivo fijado: recuperar la identidad retornando al hogar, a Ítaca, recibiendo el reconocimiento por parte de los suyos. Es decir, la subjetividad no se habrá constituido en la verdadera salida, la de Abraham, que responde 'heme aquî' e inicia un éxodo a tierras lejanas y extranjeras sabiendo que no habrá retorno posible a la tierra natal ${ }^{71}$. Nuevamente, tenemos dos modelos humanos diferentes: el ser cerrado en sí mismo, solipsista, egocéntrico; y el ser no solo abierto al otro, sino constituido como sí mismo en esa apertura, bien inherente al yo (Marcel) bien aportada por el otro (Levinas).

Esa apertura o disponibilidad, que para ser tal, ha de alcanzar su cumplimiento, requiere igualmente, según Marcel, que se dirija a otro ser personal, a un tú ${ }^{72}$. Una cosa es la apertura a la realidad y otra a los seres humanos. La relación con las cosas y la relación con los seres humanos son diferentes y no deben confundirse, ya que si sucede eso, se produce un empobrecimiento del ser humano, una pérdida de su diferencia ontológica. De

${ }_{67}$ Cfr. Marcel, G., Être et avoir (Paris: Éditions Universitaires, 1991), 48-51.

68 Cfr. Marcel, G., Homo Viator. Prolegomènes à une métaphysique de l'espérance (Paris, Présence de Gabriel Marcel, 1998), 173-174.

69 Lo propio del yo no es la apertura a lo otro, sino la desnudez del rostro. Cfr. Levinas, E., Entre nosotros. Ensayos para pensar en otro (Valencia: Pre-textos, 1993), 22.

${ }^{70}$ Levinas reflexiona sobre el significado de esta subjetividad vulnerable, que es sustitución y humildad sin ser humillación, teniendo en cuenta la Encarnación, lo que le permite, a su vez, contextualizar la noción de huella («la huella no es una palabra suplementaria: es la proximidad de Dios en el rostro de mi prójimo», Levinas, E., Entre nosotros. Ensayos para pensar en otro (Valencia: Pre-textos, 1993), 75), de desnudez e indefensión del rostro, de alteridad inasimilable y diferencia absoluta, de Deseo, de sustitución y pasividad, de responsabilidad, y de rehén y expiación; es decir, de mesianismo. Cfr. Levinas, E., Entre nosotros. Ensayos para pensar en otro (Valencia: Pre-textos, 1993), 75-78. La huella, por su parte, está unida a la Illeidad o Eleidad. Cfr. Levinas, E., La huella del otro (México: Taurus, 1998), 69-74.

${ }_{71}$ Cfr. Levinas, E., La huella del otro (México: Taurus, 1998), 54.

72 Por ello su pensamiento ha sido denominado «filosofía de la segunda persona». Leo Gabriel, «Marcel's Philosophy of the Second Person» en The Philosophy of Gabriel Marcel (Souther Illinois University, Carbondale: The Library of Living Philosophers, vol. XVIII, ed. Schilpp \& Hahn, 1984), 305. Respecto a la disponibilidad: MARCEL, G., Filosofía concreta (Madrid: Revista de Occidente, 1959), 51-72. 
ahí que no se deba llegar a la antropología desde la ontología, ni aplicar al ser humano las categorías características de la realidad sin más. Este es, como es bien sabido, el principio fundamental del personalismo: la persona es un ser diferenciado que reclama categorías propias. Igualmente este es el punto de partida del estudio de la intersubjetividad en la obra marceliana, lo que tanto valorará Levinas y lo que no significará que la antropología sea considerada como fundamento de la ontología, que es lo que Levinas objetará a Marcel y al planteamiento personalista en general: «la preocupación de la filosofía contemporánea por liberar al hombre de las categorías que únicamente se adaptan a las cosas no debe, pues, contentarse con oponer a lo estático, a lo inerte, a lo determinado de las cosas el dinamismo, la duración, la trascendencia o la libertad como esencia del hombre. No se trata tanto de oponer una esencia a otra, de decir cuál es la naturaleza humana, como de encontrar ante todo el lugar en el que el hombre deja de concernirnos a partir del horizonte del ser, es decir, de ofrecerse a nuestros poderes. El ente en cuanto tal (y no como encarnación del ser universal) no puede hallarse más que en una relación en la que se invoca. El ente es el hombre, y solo en cuanto prójimo es el hombre accesible, solo en cuanto rostro» ${ }^{73}$.

Aquí es donde se ubica la reflexión marceliana sobre el amor como conocimiento de la persona en su individualidad. Para el conocimiento abstracto y universal, que capta las cosas y al ser humano como cosa o como él, la individualidad permanece desconocida, la persona inaccesible y el sujeto encerrado en un total solipsismo. En cambio, el amor conoce la individualidad, no lo genérico, y potencia esa individualidad porque es «esencialmente el acto de una libertad que afirma otra libertad $\gg^{74}$. Eso significa que es ontológico: sin ser objetivo no es subjetivo, capta el ser del amado y lo acepta impulsándolo a que crezca. No es un conocimiento de la esencia ${ }^{75}$ - de ahí su renuncia a toda explicación exhaustiva - sino de sus posibilidades, de su capacidad de ir más allá y crear libremente nuevas realidades. Es esta capacidad de ver su ser como posibilidades que hay que cumplir la que hace que el otro sea captado como un tú y no como un él porque lo percibe como un ser que puede responder a la apelación o invocación: «no me dirijo en segunda persona más que a quien es visto por mí como susceptible de responderme, sea cual sea la manera, incluso si esa respuesta es un 'silencio inteligente'. Allí donde no es posible ninguna respuesta, no hay lugar más que para el 'él'»76.

\footnotetext{
73 Levinas, E., Entre nosotros. Ensayos para pensar en otro (Valencia: Pre-textos, 1993), 20.

74 Marcel, G., Fragments philosophiques (1909-1914) (Paris: Nauwelaerts, 1961), 97. Cfr. MARcel, G., Journal Métaphysique (Paris: Gallimard, 1997), 64.

76 Marcel, G., Journal Métaphysique (Paris: Gallimard, 1997), 137-138. Esta es una de las preocupaciones de Levinas: «nuestra respuesta es ésta: en nuestra relación con otro, ¿se trata de dejarle ser? ¿no es en su papel de interpelado donde se cumple la independencia del otro? Aquel a quien hablamos, ¿es previamente comprendido en su ser? De ningún modo. El otro no es primero objeto de comprensión y después interlocutor. Las dos relaciones se confunden. En otras palabras, la invocación del otro es inseparable de su comprensión.
} 
Este es, por tanto, el marco de la distinción entre tú y él. Cuando se está ante una persona que no está disponible, solo se puede lograr, en el mejor de los casos, información. El él es una mera fuente de información o un objeto sobre el cual el yo dialoga consigo mismo, pero el él no toma parte personal en dicho diálogo; cumple una función que podría ser realizada por una máquina. Esta progresiva funcionalización y, por ello, degradación de las relaciones interhumanas es una de las cuestiones que más preocupaban a Marcel, ya que es el núcleo de la despersonalización y el envilecimiento propio del mundo roto. En cambio, el tú es quien se siente interpelado, ha comprendido la pregunta y responde dándose a sí mismo, haciéndose presente en la respuesta. Así se establece un diálogo en el que el otro no es el tercer elemento sobre el que el yo habla consigo mismo, sino una comunicación en la verdad, no solo de la verdad, en la que dos seres personales se hacen presentes el uno a otro. Y esta es, para Marcel, una forma primaria de amor.

Si el otro aparece como un tú en el diálogo el gran problema es que sea objetivado. El tú puede muy bien mantener esa disponibilidad, pero puede suceder que el yo no la mantenga y acabe apropiándose del otro como mera fuente de información ${ }^{77}$ o que simplemente el lenguaje objetive al interlocutor. En este punto, Marcel es claramente un discípulo de Bergson y siempre tiene presente el enorme poder de cosificación u objetivación inherente al lenguaje. De ahí que, como señalara Levinas, el diálogo no sea el «momento» inicial en la relación de intersubjetividad o nosotros. Para superar la ambigüedad propia de la respuesta e ir más allá de la objetividad característica de toda respuesta y de todo diálogo, Marcel optó por calificar al tú como el ser susceptible de ser invocado $^{78}$. La invocación es la base o el elemento esencial del encuentro, de esa experiencia sumamente humana en la que se produce la apertura mutua de dos seres que hasta ese momento podían ser unos perfectos desconocidos ${ }^{79}$. Por ello, Marcel insistirá en que ese encuentro no se explica por afinidades,

Comprender a una persona ya es hablarle. Plantear la existencia de otro dejándole ser es haber aceptado ya esa existencia, haberla tomado en cuenta. 'Haber aceptado', 'haber tomado en cuenta' no remiten a una comprensión, a un dejar-ser. La palabra designa una relación original. Se trata de entender la función del lenguaje no como subordinada a la conciencia que tenemos de la presencia de otro, de su proximidad o de la comunidad con él, sino como condición de esa 'toma de conciencia'», Emmanuel Levinas, Entre nosotros. Ensayos para pensar en otro (Valencia: pre-textos, 1993), 18. Esto es precisamente lo que muestra que esta relación no es ontología, sino religión. Cfr. Levinas, E., Entre nosotros. Ensayos para pensar en otro (Valencia: pre-textos, 1993), 19.

77 «El otro en tanto que otro no existe para mí más que en tanto que yo estoy abierto a él (que es un tú), pero yo no estoy abierto a él más que en tanto que dejo de formar conmigo mismo una especie de círculo en cuyo interior alojaría de alguna manera al otro, o más bien a su idea», Gabriel Marcel, Être et avoir (Paris: Éditions Universitaires, 1991), 75.

${ }_{78}$ «Au fond cependant, toi, c'est plus essentiellement ce qui peut être invoqué par moi que ce qui est jugé capable de me répondre», Gabriel Marcel, Journal Métaphysique (Paris: Gallimard, 1997), 196.

79 La noción de invocación aparece en MARCEL, G., Journal Métaphysique (Paris: Gallimard, 1997), 169 y es uno de los temas que articulan su obra Du refus à l'invocation. 
similitudes de gustos o aficiones o por rasgos característicos de los seres que se han encontrado. Es una experiencia gratuita, un don en el que, gracias a un gesto o un detalle, dos seres se entregan en su ser, aunque solo sea por un breve período de tiempo.

Si ese encuentro, además, logra prolongarse y dar forma a esa experiencia inicial nutriéndola aparecerá la amistad o el amor. Cada una de estas formas de intersubjetividad es enriquecedora y logra poner de relieve que el yo no tiene fronteras precisas, es capaz de ir más allá de sí mismo, de crecer en nuevas direcciones, y que la toma de conciencia de sí mismo es intersubjetiva: sin el otro, el tú, el yo no sabría de lo que es capaz; el tú potencia y es el espejo en el que el yo se mira. El ser humano no es ser, es co-ser ${ }^{80}$. De ahí que el propio yo sea un don, algo que se recibe de los otros sin que exista un yo precedente que reciba los dones. El yo se constituye y toma conciencia de sí en la relación intersubjetiva y si pretende ponerse a sí mismo antes de la relación simplemente se cierra, se obtura y en esa clausura no es un ser personal porque no es capaz de apertura ni de crecimiento: sin disponibilidad no hay ni amor ni intersubjetividad y sin éstas no hay yo propiamente ${ }^{81}$.

Marcel rechazó tajantemente la propuesta individualista, según la cual cada hombre es un ser independiente de los demás, que se une a los otros con el único objetivo de conseguir alguna ventaja. Para el pensador francés la relación de cada hombre con los demás es constitutiva de su propia personalidad ${ }^{82}$. El problema es que en el mundo roto se ha perdido el verdadero sentido de la intersubjetividad, de la sociabilidad o de la comunidad, lo que ha generado una sociedad atomizada que ha menospreciado gran parte de los valores propios del ser personal ${ }^{83}$. Aunque Marcel apenas desarrolla un pensamiento sociopolítico en sentido propio, destaca la necesidad de recuperar los vínculos personales o interhumanos para poder modificar la situación de una sociedad que impide el crecimiento personal. Considera que ese cambio ha de realizarse desde la base y no desde arriba, y que ha de ir generando pequeñas comunidades unidas por lazos humanos y por objetivos y valores comunes que se irán expandiendo por el establecimiento de vínculos con otras comunidades con las que comparten esos valores y esos fines. Es decir, esta labor de humanización de la sociedad

80 «En somme, je dois penser la personnalité ontologique (et non pas, évidemment, l'individualité existante) comme postérieure à l'acte, et penser l'acte comme constitutif de la personnalité. L'amour crée l'amant en tant qu'amant. Il n'y a pas une 'nature' qui serait le sujet-substance de l'amour et dont celui-ci ne serait qu'une manifestation. Le possible qui était en 'moi' ne s'actualise et je ne suis qu'à condition de m'ouvrir aux autres en tant qu'ils sont personnes. Je ne suis que dans le co-esse», Roger Troisfontaines, De l'existence à l'être. La philosophie de Gabriel Marcel, II (Paris: Nauwelaerts, 1968) 47.

${ }_{81}$ Marcel, G., Dignité humaine et ses assises existentielles (Paris: Aubier-Montaigne, 1964), 136.

82 Cfr. Sмiтн, J., «The Individual, the Collective, and the Community» en The Philosophy of Gabriel Marcel (Souther Illinois University, Cardondale: The Library of the Living Philosophers, vol. XVIII, 1984), 337.

83 Cfr. Marcel, G., Le mystère de l'être, I (Paris: Présence de Gabriel Marcel, 1997), 36-41. 
exige para Marcel la recuperación de la comunidad o unión de personas en busca de un fin común, ya que son estas comunidades las que permitirán recuperar los valores perdidos ${ }^{84}$.

En cambio, en la filosofía de Levinas siempre hay una cierta precaución respecto a la política, a ese arte de la astucia y el engaño que ejerce violencia sobre el ser humano al intentar asimilarlo a una totalidad, especialmente cuando no se tiene en cuenta que "[el ser que piensa] existe con referencia a una totalidad, pero permanece, en cuanto yo, en su lugar, separado de la totalidad $»^{85}$. Así la sociedad no es una totalidad como una suma de seres, como una adición, sino que es «la suma de seres que no se suman unos a otros» ${ }^{86}$. Esto significa que el yo es un rostro y la sociedad una relación de seres que se hablan y se hacen frente los unos a los otros. Por tanto, el pensamiento, y con ello la sociedad, tiene como condición una conciencia moral que reconoce y piensa una libertad exterior a la propia. De ahí que la ética sea y deba ser previa a la política: «el problema de la relación entre el yo y la totalidad remite, pues, a la descripción de las condiciones morales del pensamiento» ${ }^{87}$. Y ello apela al tercero y a la justicia, pues «el tercero es el ser libre a quien puedo hacer daño forzando su libertad. La totalidad se constituye gracias al otro como tercero» ${ }^{88}$.

Aquí aparece no el tú, sino el él, el tercero; no la sociedad del nosotros, sino la justicia y con ella las instituciones: «existe una cierta medida de la violencia necesaria a partir de la justicia; pero, al hablar de justicia, hemos de admitir jueces e instituciones del Estado; vivir en un mundo de ciudadanos, y no únicamente en el orden del cara-a-cara. Por contra, solo puede hablarse de la legitimidad o no legitimidad del Estado a partir de la relación con el Rostro o de mí mismo ante otro. Un Estado en el que la relación interpersonal es imposible, donde está de antemano controlada por el determinismo propio del Estado, es un Estado totalitario. Así pues, el Estado tiene un límite» ${ }^{89}$.

A pesar de que esta tendría que ser una dimensión fundamental del pensamiento levinasiano, no es desarrollada en profundidad en su obra. El núcleo de sus reflexiones se centra en «des-montar» el sujeto para exponerlo en su vulnerabilidad, con lo que se invierte toda la metafísica y la antropología clásica —incluida la de Marcel—y se establece el principio fundamental para

84 Cfr. MARcel, G., Les hommes contre l'humain (Paris: Philosophie européenne, Editions Universitaires, 1991), 163.

85 Levinas, E., Entre nosotros. Ensayos para pensar en otro (Valencia: Pre-textos, 1993), 29. El sujeto pensante forma parte de la totalidad, permanece fuera, sin coincidir con su concepto y sin lograr su identidad por el lugar que ocupa en la totalidad. Cfr. Levinas, E., Entre nosotros. Ensayos para pensar en otro (Valencia: Pre-textos, 1993), 30.

86 Levinas, E., Entre nosotros. Ensayos para pensar en otro (Valencia: Pre-textos, 1993), 30.

87 Levinas, E., Entre nosotros. Ensayos para pensar en otro (Valencia: Pre-textos, 1993), 31. Y en otro libro dice: «la política debe poder ser siempre controlada y criticada a partir de la ética», Emmanuel Levinas, Ética e infinito (Madrid: La balsa de la Medusa, 1982), 76

88 Levinas, E., Entre nosotros. Ensayos para pensar en otro (Valencia: Pre-textos, 1993), 41.

89 Levinas, E., Entre nosotros. Ensayos para pensar en otro (Valencia: Pre-textos, 1993), 131. 
la crítica de toda sociedad que pretenda englobar al ser humano en la totalidad, explicar el sentido de lo humano por referencia a la cultura, la historia o incluso lo meramente biológico. Ante todo intento de reducción de la alteridad a la mismidad, de la trascendencia a la inmanencia, se eleva la filosofía de Levinas recordando que el otro es el extranjero, el totalmente otro irreductible que tiene, sin embargo, prioridad sobre el yo.

Como es evidente, la cuestión central es si este pensamiento de la diferencia y la alteridad absoluta no supone una grave lesión al yo, si la mismidad no es, en su desgarramiento, vaciada. Esta es la acusación de Ricoeur ${ }^{90}$ y el punto de diferencia máximo con Marcel, para quien el sujeto, sin ser soberano ni autárquico, conserva una intimidad que se ofrece como don en una apertura inherente a la propia subjetividad. De ahí que en Marcel sea posible conservar la noción de persona y establecer una comunidad de nosotros en la que ambos miembros son simétricos, la diferencia comunicable y, a la vez, no alienante si se respeta al tú sin convertirlo en él.

En cambio, Levinas apunta a una diferencia radical e irreductible que se impone en imperativo, con un sentido ético y no político, que reclama por parte del sujeto una respuesta que consiste en una responsabilidad ilimitada (aunque el pensador lituano afirma que es posible limitarla) y absoluta, de carácter radical y utópico que se opone a la creación de una sociedad de nosotros simétricos y nutrida por relaciones de igualdad, ya que en el cara-a-cara aparece la huella del tercero que reclama justicia. Para Levinas no es posible ni una comunidad cerrada ni una noción de persona, ya que «la grandeza del antihumanismo moderno - verdadero más allá de las razones que otorgue- consiste en dar un lugar claro a la subjetividad de rehén eliminando la noción de persona ${ }^{91}$; solo es posible un sujeto responsable, vulnerable, rehén en una relación diacrónica (analogía tiempo-otro) en la que el otro es la aparición del noúmeno no apresable que habla al yo en un lenguaje originario, an-árquico, que es una orden, antes que un diálogo, que exige mantener la asimetría, la heteronomía, la distancia o la trascendencia. El infinito desgarra la totalidad y no se deja absorber de ningún modo por ella; es la huella de un Decir que no se encierra en ningún dicho. Por tanto, estamos ante el humanismo del otro, en el que el otro siempre tiene el primer lugar y la primera palabra que quiebra todo egoísmo: «pero en este arrancarme de mi hipóstasis se revela el sentido último de mi 'yoidad'. [...] Se trata de que yo - a pesar de ser evidentemente primordial y hegemónico, idéntico a mí mismo en mi 'propiedad', en mi piel, en mi hic et nunc- paso a un segundo plano: me veo partir de otro, me expongo a otro, tengo que rendir cuentas. [...] la subjetividad despierta de lo egológico: del egoísmo y del egotismo [...] el yo frente a otro, se libera de sí, despierta de su sueño dogmático» ${ }^{92}$.

Teniendo en cuenta la concepción de la intersubjetividad, y volviendo a

90 Ricoevr, P., De otro modo. Lectura de "De otro modo que ser o más allá de la esencia» de Emmanuel Levinas (Barcelona: Anthropos, 1999).

91 Levinas, E., Dios, la muerte y el tiempo (Madrid: Cátedra, 1994), 218.

92 Levinas, E., Entre nosotros: ensayo para pensar en otro (Valencia: Pre-Textos, 1993), 110. 
Marcel, queda por tratar mínimamente la relación del ser humano con Dios. De igual modo que ha visto la interioridad como apertura al otro, Marcel destaca que el ser humano está abierto a Dios como a un Tú ${ }^{93}$. Esto implica superar o dejar de lado el acercamiento a un Dios racionalizado para dar paso al acceso a un Dios personal. La reflexión marceliana sobre estos temas aparece, lo mismo que el acercamiento a la intersubjetividad, en sus primeras obras en las que ya aborda el tema de la fe y de la existencia de Dios ${ }^{94}$. A diferencia de otros pensadores, Marcel considera que no se puede decir que Dios existe ni tampoco que no existe, ya que la existencia solo se aplica a lo empírico o perceptible por los sentidos ${ }^{95}$. Así pues, la imposibilidad de probar la existencia de Dios no significa su negación, sino su trascendencia: Dios trasciende lo empírico, no se relaciona directamente con lo empírico ni mantiene una relación causal con ello $^{96}$. Es decir, el pensador francés está rechazando toda la teodicea, todo acercamiento ontológico a Dios: no debe tematizarse a Dios como causa ni como ser supremo.

Frente a los planteamientos onto-teológicos, él opta por un acceso antropológico. Dios es persona y puede establecerse entre él y el creyente una relación de amor, diferente y superior a un simple razonamiento o a una prueba lógica. La fe no es un silogismo ni una demostración, sino una respuesta a una llamada. Por eso la relación entre Dios y el hombre es el diálogo: «Dios es el Tú absoluto, que no puede convertirse jamás en él. De manera que la vida espiritual es esencialmente diálogo $»^{97}$ y el diálogo es un hablar con, no un hablar de: «en el fondo, lo que yo he querido decir, es que cuando busco cómo puedo hablar de Dios, expresarme sobre Dios, soy llevado a constatar que puedo más bien hablarle que hablar de él. Y, si yo le hablo, es en efecto, como a un Tú, que no es empírico, un Tú del que yo puedo decir, por lo tanto, que es un Tú absoluto»" ${ }^{98}$. El hombre habla con Dios, no sobre Dios porque «cuando hablamos de Dios, sepamos bien que no es de Dios de quien hablamos ${ }^{99}$.

De ahí la afirmación marceliana que establece la imposibilidad de la teodicea. No hay discurso posible sobre Dios porque Este es incaracterizable, no puede

93 Cfr. Marcel, G., Journal Métaphysique (Paris: Gallimard, 1997), 265, 273-276.

94 Cfr. Marcel, G., Journal Métaphysique (Paris: Gallimard, 1997), 7. Cfr. MARcel, G., Être et avoir (Paris: Éditions Universitaires, 1991), 147-157.

95 Cfr. MARcel, G., Journal Métaphysique (Paris: Gallimard, 1997), 34.

96 Marcel rechazó el creacionismo, ya que, según él, Dios no puede tener una relación directa con el orden de lo existente. Cfr. Marcel, G., Journal Métaphysique (Paris: Gallimard, 1997), 36.

${ }_{97}$ Marcel, G., Journal Métaphysique (Paris: Gallimard, 1997), 136-137. La crítica a la prueba ontológica de la existencia de Dios, así como la conexión de la fe y la existencia de Dios se encuentra en MARcel, G., Journal Métaphysique (Paris: Gallimard, 1997), 33-36.

98 Marcel, G., Gabriel Marcel interrogé par Pierre Boutang (Paris: Editions J. M. Place, 1977), 70. El lenguaje sobre Dios debe ser oblicuo y no objetivante. Cfr. Blázouez Carmona, F., La filosofía de Gabriel Marcel. De la dialéctica a la invocación (Madrid: Encuentro Ediciones, 1988), 195. A pesar de haber dicho que Dios es un Tú absoluto, Marcel tenía dudas respecto a si se podía decir que es un Yo absoluto. Cfr. Gabriel Marcel interrogé par Pierre Boutang (Paris: Editions J. M. Place, 1977), 70-71.

99 Marcel, G., Journal Métaphysique (Paris: Gallimard, 1997), 158. 
ser asimilado a un sujeto de determinaciones susceptibles de figurar como predicados de un juicio ${ }^{100}$. Además, esta negación es un intento de no perder el carácter personal de Dios, puesto que para Marcel una teodicea presentada como un discurso convierte a Dios en un «él» ${ }^{101}$. Toda teodicea es un mero intento de apresar a Dios mediante características hechas a la medida del ser humano, pero «Dios no puede serme dado más que como Presencia absoluta en la adoración; toda idea que me forme de él no es más que una expresión abstracta, una intelectualización de esta presencia, y es de esto de lo que debo acordarme siempre que busco manipular estas ideas, sin lo cual éstas acaban por desnaturalizarse entre mis manos sacrílegas» ${ }^{102}$. La teodicea para Marcel es esencialmente negativa, no puede decir lo que Dios es porque los conceptos son inadecuados ${ }^{103}$.

Marcel afirmó que no intentaba negar la realidad de Dios, sino destacar su transcendencia y la insuficiencia de los razonamientos lógicos para alcanzarlo. Según él, la filosofía debe ser un acercamiento amoroso a Dios, de lo que se sigue que la frontera entre la filosofía y la mística es imprecisable ${ }^{104}$. Sin embargo, el francés subrayó que su propuesta de hablar de Dios en segunda persona y no en tercera persona seguía siendo filosofía, no religión ${ }^{105}$. La filosofía no puede renunciar al tú, porque «si negamos que el orden del tú pertenezca al ámbito de la filosofía propiamente dicha, nos veremos probablemente obligados a dejar la filosofía en un plano anterior al pensamiento existencial tal como se ha desarrollado desde hace medio siglo y cuya fecundidad me parece absolutamente fuera de duda» ${ }^{106}$. También para Levinas el primado de la ética es filosófico ${ }^{107}$.

Cuando Levinas leyó estas afirmaciones de Marcel, por una parte, compartió la necesidad de superar y rechazar el tratamiento ontoteológico de Dios; pero, por otra, no aceptó su abordaje como un Tú: «el fiel comienza por decir a Dios 'tú' y termina la proposición comenzada diciendo 'él', como si, en el curso de este acercamiento al 'ti', sobreviniera su trascendencia en 'él'» ${ }^{108}$. A pesar del avance que supone el planteamiento marceliano, Levinas considera que «Marcel está interesado en prolongar la ontología tradicional: Dios es el ser. La idea de que Dios es de otro modo que ser, de que está más allá del ser, como

100 Cfr. Marcel, G., Journal Métaphysique (Paris: Gallimard, 1997), 65.

101 Cfr. De l'existence à l'être. La philosophie de Gabriel Marcel, II (Paris: Nauwelaerts, 1968), 210.

${ }_{102}$ Marcel, G., Etre et Avoir (Paris: Éditions Universitaires, 1991), 122.

103 Cfr. Marcel, G., Etre et Avoir (Paris: Éditions Universitaires, 1991), 86. De esta forma Marcel se inscribe dentro de aquella tradición de pensamiento cristiano que afirma que la teología es principalmente negativa. Cfr. Blázouez Carmona, F., La filosofía de Gabriel Marcel. De la dialéctica a la invocación (Madrid: Encuentro Ediciones, 1988), 190.

104 Cfr. Filosofía concreta (Madrid: Revista de Occidente, 1959), 190.

105 Cfr. Marcel, G., Filosofía para un tiempo de crisis, (Madrid: Guadarrama, 1971), 35.

106 MARCEL, G., Incredulidad y Fe (Madrid: Guadarrama, 1971), 178.

107 Cfr. Levinas, E., La huella del otro (México: Taurus, 1998), 98.

108 Levinas, E., Ética e infinito (Madrid: La balsa de la Medusa, 1982), 99. 
dice Marion [...], le hubiera escandalizado» ${ }^{109}$. Frente a esto, Levinas sostendrá que el único acceso a Dios no es ni siquiera la negación, ya que no aceptará la teología negativa, sino el otro, aunque es necesario no perder de vista "que esta trascendencia se produzca a partir de la relación (¿horizontal?) con Otro no significa ni que el otro hombre sea Dios ni que Dios sea un gran Otro» ${ }^{110}$. En el rostro del otro, en su vulnerabilidad, aparece la huella de Dios, de lo infinito que se acerca, que viene a la idea, pero que Dios venga a la idea no puede ser leído de forma teísta ${ }^{111}$. Dios mantiene siempre su lejanía, puesto que se trata de «un Dios que es un El» $»^{112}$.

Por tanto, en el tratamiento de Dios, de la relación con Dios, Levinas sigue dando prioridad a la alteridad, a la trascendencia, que viene a la idea y quiebra la totalidad, pero no puede ser englobada bajo las nociones de "yo», «tú» o «nosotros». De ahí que, a diferencia de Marcel, el uso del nosotros sea problemático en Levinas o, al menos, no signifique el plural del yo, sino la responsabilidad que constituye al yo como tal. Por ello sería mejor conservar su propia terminología para referirse a las relaciones interhumanas o las relaciones intersubjetivas con Dios en las que no hay un tú, sino un él, no hay simetría sino asimetría y no hay en primer lugar libertad sino mandato; es decir, no hay humanismo clásico, sino humanismo del otro.

En conclusión, los planteamientos filosóficos de Marcel y Levinas, vistos desde el tratamiento que llevan a cabo de las relaciones interhumanas, se alejan el uno del otro. Si bien ambos parten de la crítica a la filosofía anterior, entendida como un modo de pensar que no aborda correctamente el ser del hombre, y que Levinas se apoyara en Marcel para dar un paso más; ese ir más allá del ser no es compartido por el filósofo de la intersubjetividad. El ser humano, para Marcel, no debe ser comprendido desde la ontología, pero su apertura y su intersubjetividad no rasgan su ser ni dinamitan su carácter de sujeto. Sin embargo, Levinas destacará que la apertura es producida por el otro y que el yo es pasividad que se desagarra y se transforma en una responsabilidad que no responde únicamente de las acciones de un supuesto sujeto. Es decir, Marcel conserva las nociones de sujeto y especialmente de persona, incidiendo en su intersubjetividad. Levinas busca una salida del ser, un fuera del sujeto y eso le conduce a la alteridad radical y absoluta.

Departamento de Filosofía.

JULIA URABAYEN

ICS. Universidad de Navarra

jurabayen@unav.es

[Artículo aprobado para publicación en noviembre de 2013]

\footnotetext{
109 Levinas, E., Entre nosotros. Ensayos para pensar en otro (Valencia: Pre-textos, 1993),

110 Levinas, E., Entre nosotros: ensayo para pensar en otro (Valencia: Pre-Textos, 1993), 95-96.

111 Cfr. Levinas, E., La huella del otro (México: Taurus, 1998), 101.

112 Levinas, E., La huella del otro (México: Taurus, 1998), 110.
} 145. 